\title{
How should we deal with submissions from the Global South? An Editorial
}

\author{
Thomas W. Guenther ${ }^{1}$ (D)
}

Accepted: 8 September 2020

(c) The Author(s) 2020

The structure of submissions to the Journal of Management Control has changed tremendously during the last 5 years. Similar to other academic journals, we receive an increasing number of submissions from the so-called Global South; that is, from Africa, South America and South and South East Asia. Literature reviews show that publications from North America, Europe and Australia/New Zealand dominate our research areas. This is, however, changing with the higher education institutions in the Global South developing strongly and producing talented and ambitious scholars who enter the market.

The Journal of Management Control, like other journals, has received hundreds of submissions over the last few years, many from the Global South. These papers very often contain good data, address interesting and innovative topics as well as use adequate or up-to-date statistical methods, but are ultimately not published. They are rejected after being peer-reviewed or almost immediately desk-rejected by the editors without even sending the submissions out for review. As the managing editor of the Journal of Management Control, I personally find this unsatisfactory and disappointing, because the outcome seems to be at least partially predictable.

To make it perfectly clear: each submission has to fulfil the same, high quality publication standards without any reference to the papers or their authors' country of origin. The double-blind review process allows us to focus on relevance for practice and research, but also on the scholarly rigor representing the complex and multifacetted standards of high quality publications.

What are rejected papers' major shortcomings? These papers often do not meet an academic journal's scope, which, in the Journal of Management Control's case, is management accounting and management control as well as their interfaces with other research fields. Many papers are too short, often only 15-20 pages, which does not allow to reveal the presented research's quality. The literature reviews in these papers are often biased in favour of local authors and often do not consider the field's worldwide knowledge, which is required to make a contribution to the (worldwide) literature. All too often, hypotheses are presented, but not derived from

Thomas W. Guenther

thomas.guenther@tu-dresden.de

1 Technische Universität Dresden, Dresden, Germany 
the theoretical or empirical literature. Even when advanced empirical methods, such as structural equation modelling or fsQCA, are used, the papers often lack robustness checks, alternative models or detail levels. Conclusion sections simply summarize the results without discussing how they reflect or differ from the theoretical foundations or other empirical evidence.

Reviewers are usually very sceptical when faced with such shortcomings and tend to reject such papers, reflecting our journal's objectives. Nevertheless, many of us from the Western world learn to frame our papers and avoid these pitfalls in two-year or three-year Ph.D. programmes, academic workshops and brownbag sessions-opportunities many Global South scholars never have.

Consequently, I feel personally obliged to reach out and guide authors to improve their papers. However, I know this is not easily done. Reviewers' willingness to go the extra mile to provide guidance and hints regarding the relevant literature, methods and organization of papers is limited, given that this would entail more work and longer reviews. Reviewers who want to accept this additional burden of teaching good research practice are therefore more than welcome to do so. On the other hand, this first of all requires the relevant authors to be willing to respond adequately and in detail to such reviewers, to really follow all of the reviewers' comments and hints to develop the paper further and to stick to a reasonable time frame. This needs more time and perhaps an extra round in the review process. Patience and willingness to learn are necessary. I remember a young Asian Ph.D. student who asked me: "Professor, can you please teach me?" which left me honoured, but also somewhat puzzled.

The point is that the editors of the Journal of Management Control are open to suggestions on how to solve the problems and how to inspire research from the Global South.

This Journal of Management Control issue is - more by chance than by intentioncharacterized by the endeavour "to stand on the shoulders of giants". This saying has been traced back to Bernard of Chartres in the 12th century, but is also linked to Isaac Newton in 1675. This means basing future research on the treasure and wealth of existing research in order to find research gaps, to ground our research, and to aggregate what we know so far. Three of the four papers in this issue are therefore literature reviews.

Kohsuke Matsuoka explores customer accounting that is, accounting techniques using customer data. He conducts a literature review, addressing in detail revenue accounting aimed at the planning and control of marketing; customer profitability analysis as a stream of strategic management accounting that addresses the allocation of selling, general and administrative expenses to individual customers through activity-based costing; and customer lifetime value and customer equity focusing on the present value of cash flow from customer acquisition and retention.

Recent developments in digital technology have fostered interest in the relationship between technology and management accounting. In a case study building on the jurisdiction concept, Roy-Ivar Andreassen explores the relationship between management accountants, expert knowledge and digital technology. The study describes the shift divisional management accountants are experiencing towards narrower roles in their tasks and expectations, while business-oriented roles at the group level reveal expanding tasks and expectations. The case study in the technology-oriented finance sector contributes in a number of ways to the debate on management accountants' roles. 
Despite the growing interest in research on internal control, both theory and practice are confused about the concept. The study by Oliver Henk addresses this lack of clarity by systematically structuring the literature referring to the internal control concept, investigating what previous studies on the practice of internal control have taught us, and how internal control is institutionalized. The paper uses 'institutional work' as a theoretical lens to analyse the existing literature in the field. The literature review reveals that the understanding of internal control is currently divided: one part of the literature understands the concept as internal control of financial reporting, while the other part has a more global and strategic understanding of the term.

A diverse set of source disciplines has for decades informed management accounting and control researchers to predict and examine behaviour. Psychology is among the most frequently drawn upon of these disciplines. Although the literature confirms that psychological theories are highly relevant for management control research, the existing knowledge of this field remains rather fragmented. Given this background, Lisa-Marie Wibbeke and Maik Lachmann examine recent management accounting and control research through a systematic review of the different subfields of psychology to investigate the development of this stream of research. They collected 125 articles from nine leading accounting journals between 2000 and 2019 and analysed their contents. On this basis, the authors provide a detailed overview of the use of psychological theories in recent literature and identify links between specific theories and management accounting and control topics.

With these four papers we hope to contribute to the management accounting and control literature. By "standing on the shoulders of giants", these studies might aggregate existing knowledge in the field and inspire other scholars to further develop our field of management accounting and control.

Dresden, September 2020

For the team of editors

Thomas W. Guenther

Frank Verbeeten

Managing editors

Funding Open Access funding enabled and organized by Projekt DEAL.

Open Access This article is licensed under a Creative Commons Attribution 4.0 International License, which permits use, sharing, adaptation, distribution and reproduction in any medium or format, as long as you give appropriate credit to the original author(s) and the source, provide a link to the Creative Commons licence, and indicate if changes were made. The images or other third party material in this article are included in the article's Creative Commons licence, unless indicated otherwise in a credit line to the material. If material is not included in the article's Creative Commons licence and your intended use is not permitted by statutory regulation or exceeds the permitted use, you will need to obtain permission directly from the copyright holder. To view a copy of this licence, visit http://creativecommons.org/ licenses/by/4.0/.

Publisher's Note Springer Nature remains neutral with regard to jurisdictional claims in published maps and institutional affiliations. 